\title{
"Dwelling" through the concepts of ground, wall and canopy: a fragmented application in design
}

\author{
S. Ozcelik Guney \\ Faculty of Architecture, Gebze Technical University, Turkey
}

\begin{abstract}
This paper is concerned with second year undergraduate architecture design studio works regarding the notion "to dwell". The two main features of a dwelling are taken into account: the first is the physical formation of a space with three main elements, namely, ground, wall and canopy; the second refers to the social aspects, that is, user profile, demands, and integration of dwelling design with the surrounding built environment. The former refers to a tangible form as the latter provides insight for the abstract components of the dwelling. The word "abstract" stands for the psychological, economic, demographical and social aspects of the dwelling and used for addressing such notions. The aim of the study is to explore the comprehension and response of students with respect to abstract and physical issues in housing design. The outcomes of a 14-week-studio period are assessed by a set of parameters. The study has explored the notion of a house as a design object, as well as a social venue. Qualitative interpretivist methodology is used to carry out a comprehensive design evaluation. Analysis refers to the complex nature of the subjective experience of individuals with regard the places they inhabit. Thirteen students works that passed the semester with grades higher than 75 out of 100 have been assessed regarding (1) users and function, (2) building form and, (3) urban planning conditions. The first criterion is related to the abstract aspects of dwelling; the other two refer to tangible design aspects. This paper presents the interpretations of the assessments of the final works based on the notes taken by researchers and lecturers during the studio periods, and the statements of students about the design exercises. The design tasks enabled students to confront the challenge of giving meaning to abstract notions of dwelling in the early architectural education stages. A majority could cope with the tangible formal issues of a design. However, issues such as user demands, social aspects, sense of
\end{abstract}


privacy, shared spaces, and interaction with the neighbourhood were found to be challenging and hard for students to understand.

Keywords: architectural design studio, fragmented teaching methodology, dwelling.

\section{Introduction}

Teaching creativity in design conveys the exploration of multiple approaches in an environment that supports experimentation. Design is a "sophisticated mental process" [1] being nourished by different sets of knowledge. A critical approach to design furnishes new insights and perspectives. This explains why the design studio is often referred as an "intellectual atmosphere" [2]. Critical thinking is enhanced by establishing connections between seemingly unrelated issues. Abstract notions lead to tangible products whereas the meanings that the final products carry are still abstract and intuitive.

The second year undergraduate design studio aimed at approaching from multiple perspectives a very conventional design problem: a single house design in the urban context. Due to a complex urban setting, the Salacak/Uskudar district in Istanbul, with historical parts, a diverse demography, diverse traffic and transport systems, sea fronts, and views, was the area selected to carry out the design projects.

The purpose of the study is to explore how students integrate abstract (possible scenario, household profile, demands and characteristics) and physical notions (forms, patterns and materials) in their design solutions. Due to difficulty intrinsic to the notion of dwelling, students were challenged to come up with the "design question". Reflecting on the design question behind dwelling raises awareness of social and political systems and creates consciousness about the powers of domination [3]. Focusing on how to convert abstract concepts into concrete design proposals enhances awareness of social aspects and prevents from creating housing forms as mere "sculptures".

Larrive identifies three practices that are essential for design teaching: making time for solitary re-action, becoming a perpetual problem solver and questioning the status quo [4]. The methodology we have adopted to analyse the design thinking of students is based on ethnographical research in which the teacher also acts as observer of the process. Moreover, this methodology helps to distinguish between the end products and the continuum of works created along the design process [5-10].

The students' works are assessed with respect to user/function, form and master plan criteria. The assessments refer to previous literature such as the study by Walliss and Greig [11] which analyses the student attitudes and responses obtained from focus groups during the teaching process. The difficulties students have to understand some of the architectural concepts can be detected in this way. The study shows that the ground/wall/canopy elements are used explicitly in the design. Moreover, the design solutions by the students to the user/function and master plan requirements, which are rather abstract questions such as social, economic, demographic and physiological issues. These aspects are found to be 
somewhat "neglected" by the students due to their intricacies. The concrete design components are shaped easily (ground, wall and canopy) since the form is "simple to follow" contrary to these abstract issues. Moreover they might be formulated without considering the other issues attached to the dwelling phenomena. Thus the setting is perceived as a simple ground where the house will be erected.

\section{Teaching through abstract notions}

The architectural design studio is the place for experimentation and inquiry, as opposed to learning commonly accepted knowledge. Design studio teaching demands authenticity. It is not enough to share architectural knowledge by narration; the studio is a platform for probation and discussion. The distance between teacher and student roles is a problematic in a design studio, because it contradicts its experimental nature. Another separation to overcome is the one that exists between design requirements and design object.

Freire [6] refers to the relationship between student and teacher as "dialogue", as a practice of freedom. Invoking each one's experience and placing it in context is the essence of this dialogue. Contrary to discussion, dialogue is a type of humble, open, and focused speech in a collaborative learning context. Communication contributes to enhance the consciousness about this dialogue.

This sort of reflection in action gives rise to a knowledge that is not an "exact science" [12]. Dewey [13] defines reflection as "an active, persistent and careful consideration of any belief or supposed form of knowledge". The student is guided by the tutor in the construction of the problem, the definition of the strategies of the action and the formulation of "the model of the phenomena" [14, 15]. Critical theory is grounded in the Frankfurt school, which turn was based on Gramsci's concepts of hegemony, subject, and counter-hegemonic practice; politics of ethics, difference, and democracy [16].

There are various approaches to the problem. For instance, some design teaching methodologies are created by using the Learning Design Studio (LDS) methodology. This methodology is based on the teaching strategies followed during the semester in which students work in groups on a design in a specific domain of practice [17]. LDS aims at forming professionals of education in the learning design inquiry [18]. In this learning context, teachers play the role of social mediator, learning facilitator, and re-active practitioner [19]. The problem domain encompasses different levels of "design abstractions, spaces and variables" [20].

Lawson describes design as a "sophisticated mental process" involving diverse information whose goal is to provide a coherent idea which then becomes materialized [21]. The role of teacher is crucial since providing strong guidelines might ruin the creativity of the student; while leaving ideas too loose in the students' minds might lead to a loss of the focus on the design task and the subsequent disinterest. 


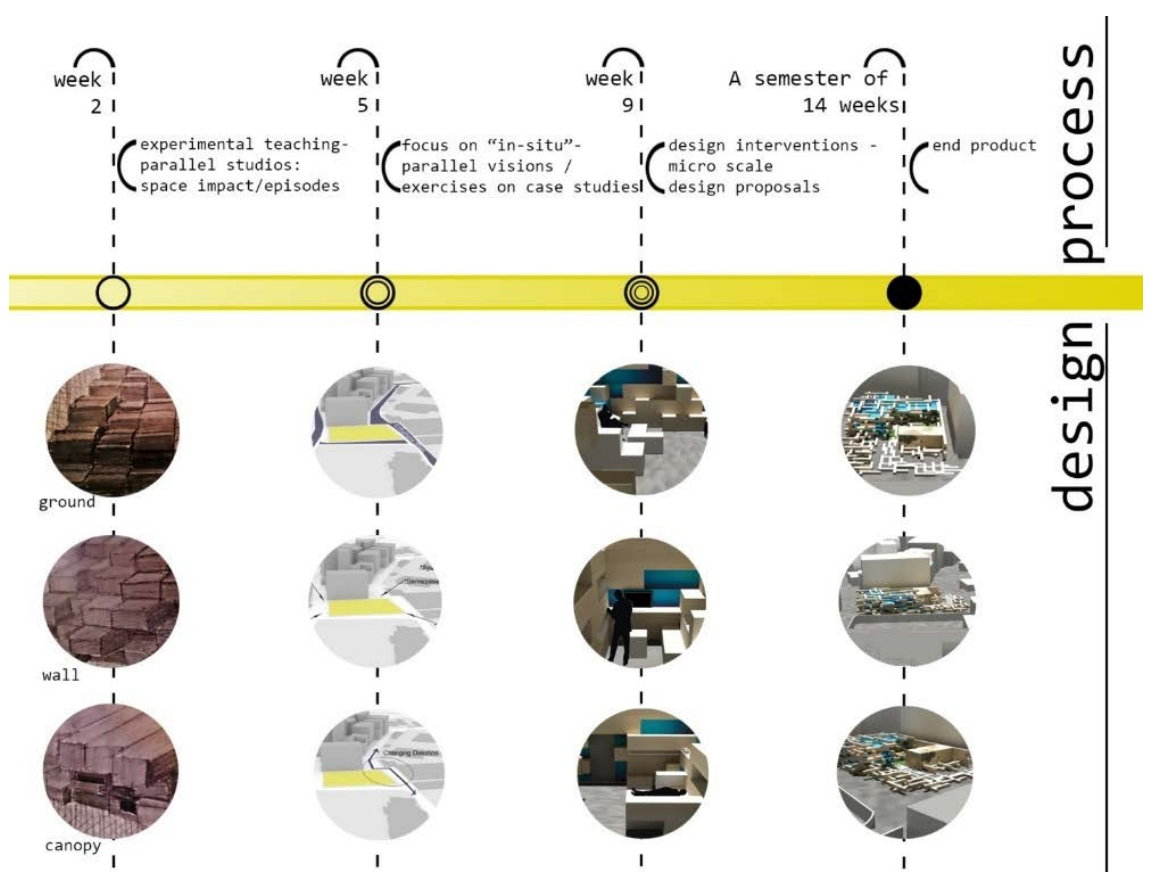

Figure 1: The sequence of fragments in the design process period of 14 weeks.

The 14 weeks of the semester are divided into three main parts. Students elaborate the designs through a series of workshops in the first three weeks of the program [22]. The phases in design are named as elements by Shaffer [23]. The three parts are similar to the Shaffer's element and named as fragments in this study:

(1) Experimental teaching - episodes. In a first episode, the topography and texture of the ground element are explored. The second episode is dedicated to the spatial formulation of the wall (surface) thriving from a ground continuum. The third episode focuses on the canopy element to conclude with the ground-wall continuity.

(2) Focus on the site. In this fragment, exercises are carried out to collect design inputs from the analysis of the location, Uskudar.

(3) Design interventions. This fragment focuses on micro scale design proposals. It is the stance of the student acting as an architect who builds a re-action in accordance to the nature of the problem. It is a parallel approach to the one adopted by Brookfield who referred to the critical re-action as a case of "stance and dance"; "dance" implying an action in rhythm [24] (Figure 1). 


\section{The design question}

Rapoport [25] highlights the value of the thresholds between inside and outside territories. The intersection of spaces offers the opportunities for interaction or isolation, for dwelling in multiple ways [25-27]. A dwelling programme is crucial since it defines the inside, while letting other spaces outside. The studio topic the lonely man's shelter, which embraces the idea of minimal usages and sizes in domestic space. Instead of giving to the student a pre-established housing programme, a set of terms are put forward describing the dweller. For instance, guest friendly refers a living area with a dinner table or architect refers to a small workspace.

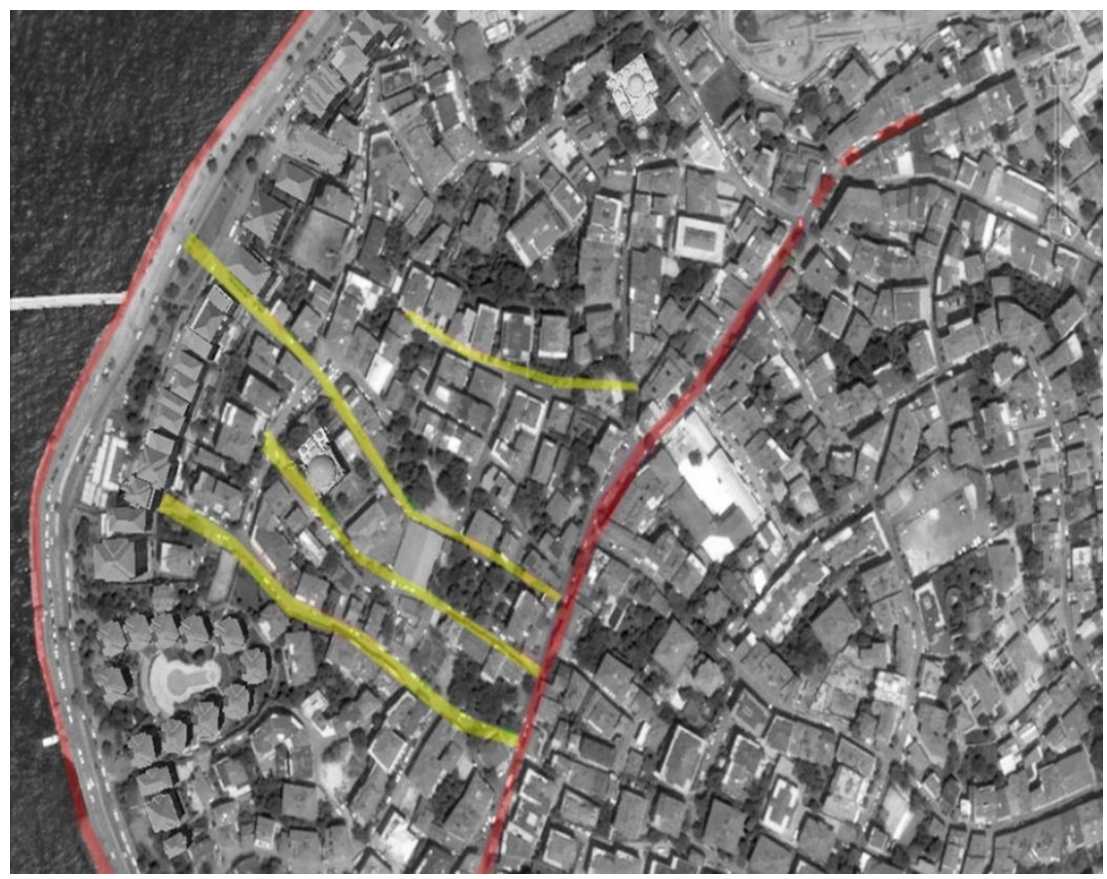

Figure 2: Map of the site, the design study lines are displayed in green and the borders in red, Ayazma District, Uskudar/Istanbul.

Uskudar is the area selected for the projects. It is one of the main districts of Istanbul, located on the Asian side. The district contains one of the three main transportation arteries. Ayazma, the selected spot, is a historical neighbourhood dating back to Constantinople of Byzantium periods. The road lines are identified as part of the design formulation process instead of addressing particular building lots or land plots (highlighted in green, Figure 2). Every perpendicular road leads to the waterfronts, a significant feature in Istanbul since the buildings are placed to avoid the uninterrupted view of the sea (Figure 2). Urban patterns, historical elements and social activities were studied. 


\section{Research approach}

The research question we posed was: "Is making meaning of abstract notions more difficult than the tangible notions for students at the early stages of architectural education?" Our study is based on an interpretivist qualitative research approach. The data are the final projects, studio notes and contributions of students to the round table dialogues and in focus group discussions. Interpretive analysis and descriptive presentations give meaning to the data. The works made by students along the design process are assessed in terms of user/function, form and adherence to the master plan using a systematic framework (Table 1). It should be noted that due to the nature of the study, "discrete hypotheses, results, and conclusions" are not presented [23]. Rather, we are presenting the work done in a design studio during one semester in a systematic manner. This research approach is similar to the one adopted by most studies on the design teaching, conducted by qualitative research taking the ethnographic perspective [11, 23, 28-30].

Ehmann displays an example of a successful trial of a non-standard educational domain by using a particular assessment and feedback mechanism originating from the creative areas [31]. Similar to this sample selection, the assessment of this study focused on 13 works out of 33 submitted final proposals. The works were selected according to the grades received (the highest three grades under the university grading system).

\section{Issues to evaluate}

Evaluations of the works are conducted regarding the criteria user/function, user profile and spatial configurations. The sub-categories attached to these criteria are listed in Table 1. The figures with the project numbers give the design approach of each project. It should be noted that these figures are used only to give a general idea of the design proposals. The main criteria are explained in the following sections:

\subsection{User/function}

The user's needs are reflected in the dwelling's functionalities. This criterion captures the abstract features of a house and it enables to assess to which extent psychological, social and phenomenological issues have been considered. This criterion refers to what surrounding built environment offers and the user requires from the dwelling considering the settlement. It is a crucial interface that the house becomes a social venue for the neighbourhood as well as the individual user.

\subsubsection{User profile}

The user profile corresponds to a single "introvert" dweller living in an urban environment as the one described. The integration between the user's aspirations and what the dwelling offers are evaluated in relation to the indoors and interior functioning of the house. These can be tailor-made and very personal considering the special functions of a house that is designed for a single person. 


\subsubsection{Spatial configurations}

Dwelling interlinks spaces and functions, indoors and outdoors. This innovative notion of space, which goes beyond the traditional room, is evaluated.

Table 1: The three main assessment criteria fulfilled in the design proposals displayed in numbers from 1 to 13 .

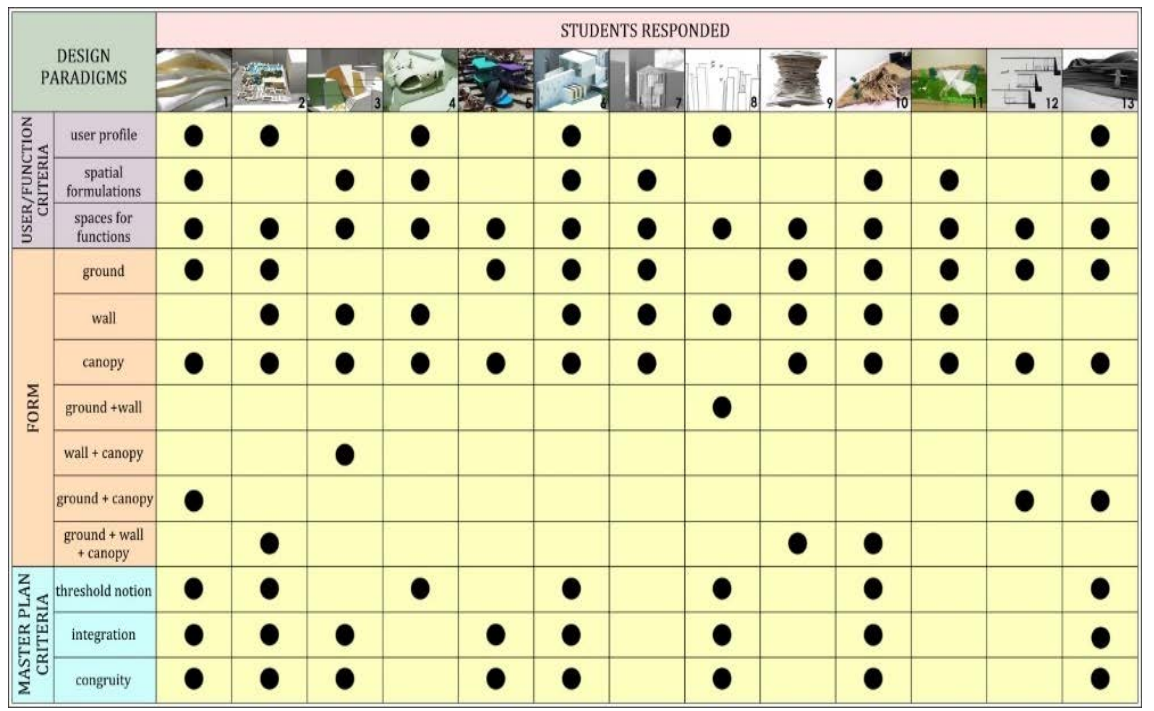

\subsubsection{Spaces for functions}

The issues to assess are the flow of space resulting from the activities, the interpretation of the open plan concept, the integration of similar functions and an open approach to space.

As the projects were analysed, it could not be concluded that a design which fulfils the user/function criteria also complies with the urban planning requirements (project numbers 4, 7 and 11). This may infer to the design subject as a "shell" considering the form. Even though the personality of the user is described through adjectives in the design question, the notion of "user profile" is mostly neglected in the projects, as students mostly consider the conventional questions and neglect the user's requirements.

Spaces which fulfil a specific function are taken as the component parts of a dwelling. Accordingly, it is observed that the functions in a housing program are taken as a "checklist" that the house design must comply. Nevertheless, few proposals suggest innovations in the way a dwelling functions in spatial terms. Thus, the User/function criteria refer to coherent relations in almost half of the proposals (design numbers 1, 3, 4, 6, 7, 11 and 13) (Figures 3-5). It can be inferred that the connection between the built environment and the dwelling are considered in a conventional way. The architectural form is considered but the social functions of the dwelling are neglected. A student explains that the challenge is to match the form and the functions: 


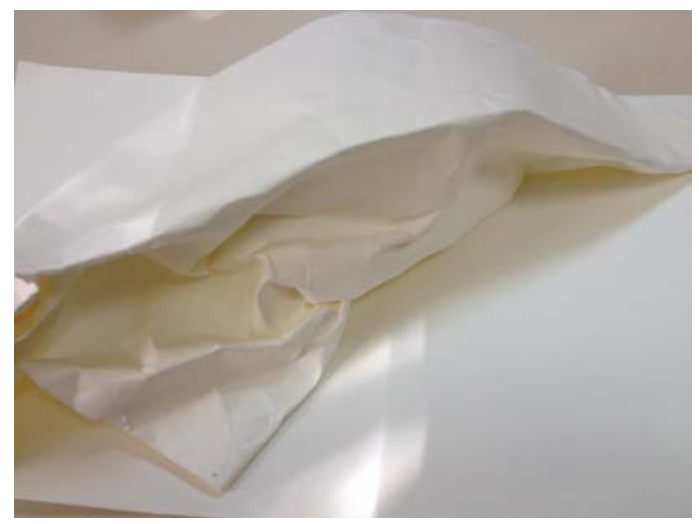

Figure 3: Project number 1, wall proposal.

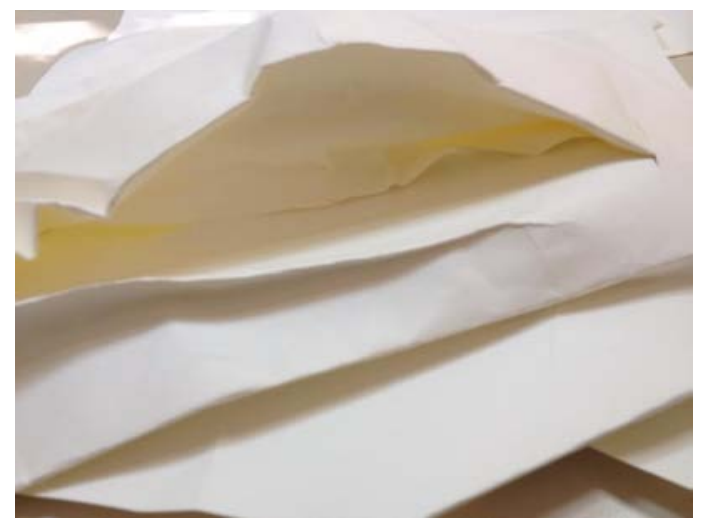

Figure 4: Project number 1, combined design proposal for ground, wall and canopy elements.

We always focus on the dwelling as a sculpture, once the functions are placed in the building. ... The idea of the form gets to be distorted. It was not what I imagined at the beginning.

Moreover, designing a house in a dense urban tissue was also found to be difficult:

Functions and usage are very compelling as such small plots are taken as case studies. It was very difficult to plan everything.

It was difficult for student to propose concrete solutions for an urban living corresponding to a particular user. 


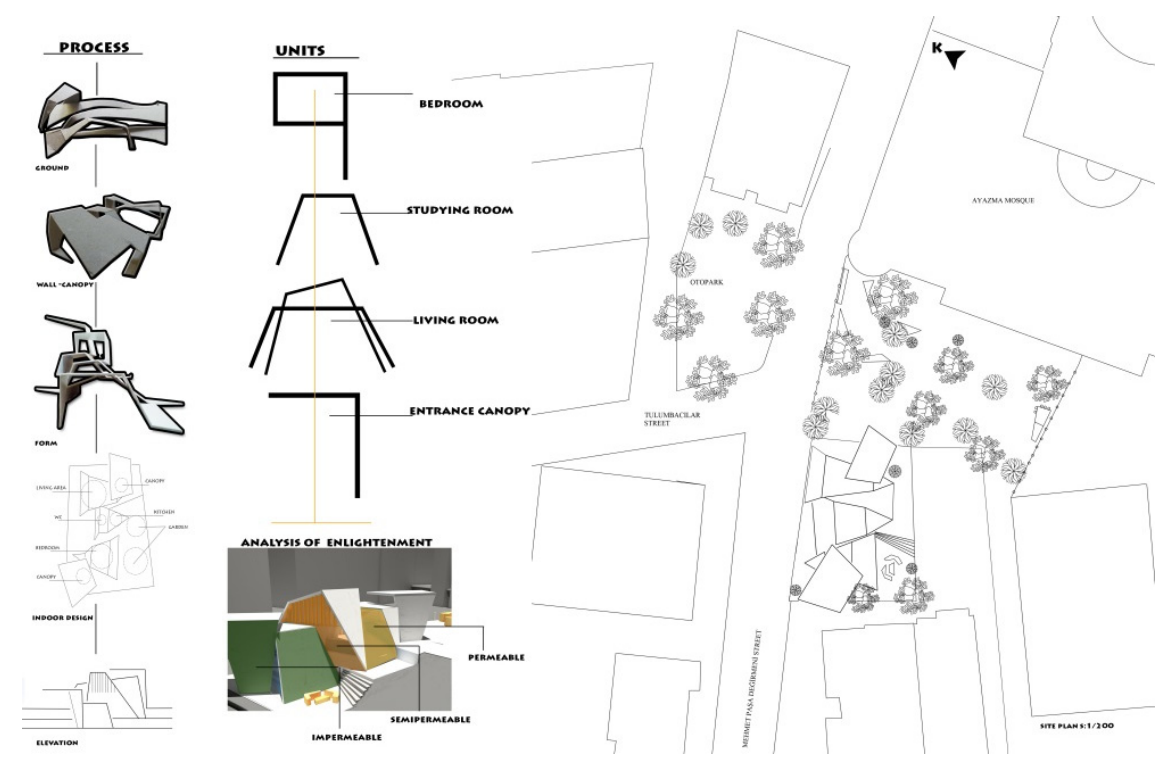

Figure 5: Project number 3, the design development of the proposal.

\subsection{Form}

Form concept stands for the physical formation of a building. In this study, form is considered to be isolated from social, psychological and economical aspects of the dwelling. Only the connections between the dwellings with the outdoor spaces are also considered to be a part of the form. Moreover, the continuum of the functions in the dwelling is linked with the form. The notion of form is detected through ground, wall and canopy elements of the building. The appraisal of horizontality and floor layout, and its coherence with the terrain. The notion of ground considered as the driver of the dwelling's form.

\subsubsection{Wall}

The vertical link with the ground, the expression of scale, and the coherence between height and function, are evaluated.

\subsubsection{Canopy}

The extension of a form to create a shelter, the continuity of ground and wall are the issues to be considered. The metaphor "peeling the ground" is used to create the canopy element. Protection from climate (sunlight, wind, humidity), creation of a sense of privacy, and provision of a second layer above the ground are studied.

Table 1 shows that the works which fulfil the design requirements for the form criteria also satisfy the conditions required for the architectural elements mentioned (ground, wall and canopy are considered to be the architectural elements). These projects also meet the master plan and user/function criteria in most cases (design numbers 1, 2, 3, 5, 6, 8, 10, and 13) (Figures 6-11). 


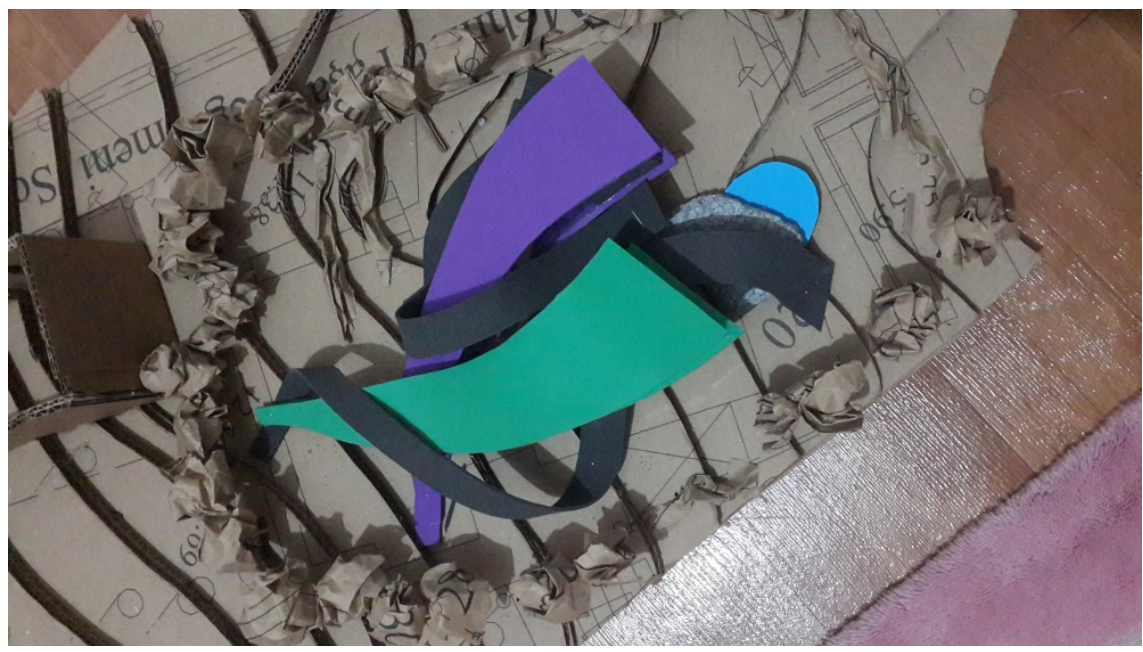

Figure 6: Project number 5, final design proposal. Ground elements is extruded as a canopy.

In some cases (design numbers 4, 5, 8, 12 and 13) (Figures 8-10), even though ground, wall and canopy elements are formulated individually, the final proposals have achieved a holistic design approach. Moreover; in some cases one particular architectural element has "guided" the general design.

In projects 6,7 and 11 , the ground, wall and canopy that fulfil the single element design proposals do not comply with the integration of two or more elements. However; those proposals achieved significant results fulfilling other criteria. This may imply that, contrary to the assumptions of the tutors that a house can be designed by combining three main elements (ground, wall and canopy), each element can generate form by itself, independently from the other two.

In the project number 8 , the ground and canopy formulations are not coherent to each other. The design proposals do not carry certain potentials to guide a whole design proposal. However; one student grasped the design tendency in the Wall Episode and continued developing the proposal through this track and fulfilled the entire other criteria demanded.

Project number 3 is the only proposal resulting from the integration of wall and canopy elements (Figure 5). Nevertheless, the abstract notion of threshold cannot be appreciated in this proposal. It can be inferred that the abstract nature of threshold and ground element have similar connotations.

During the round-table discussions at the studio, one student stated:

It is very easy to come up with form proposals. But as the neighbourhood is re-visited, you can see that the design should be revised.

Tangible elements are easy to produce regardless of the complexity of the urban context. In addition, even if the models were designed with respect to certain scale frames, it was difficult for students to imagine the actual sizes: 


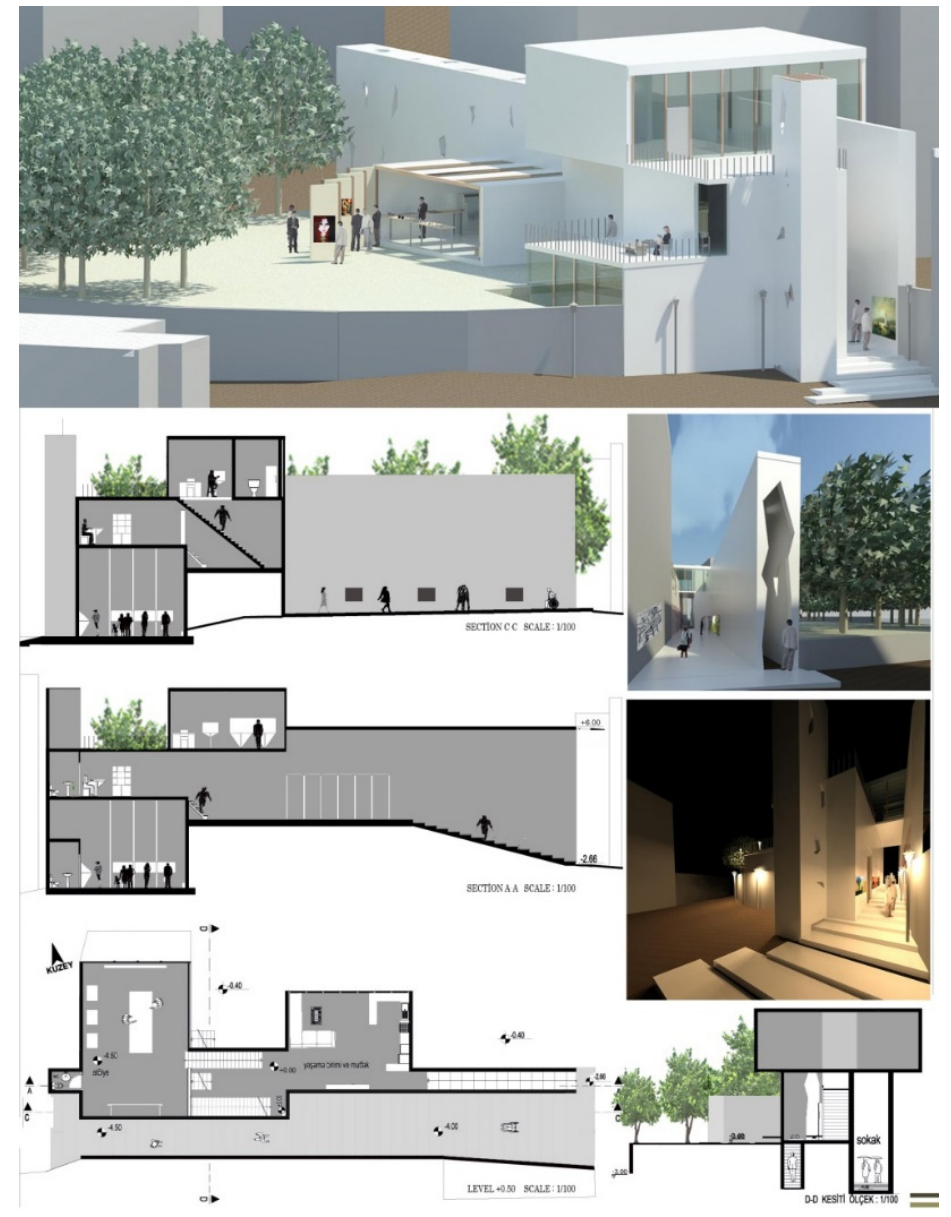

Figure 7: Project number 6, the intersections of the walls creates the final design proposal.

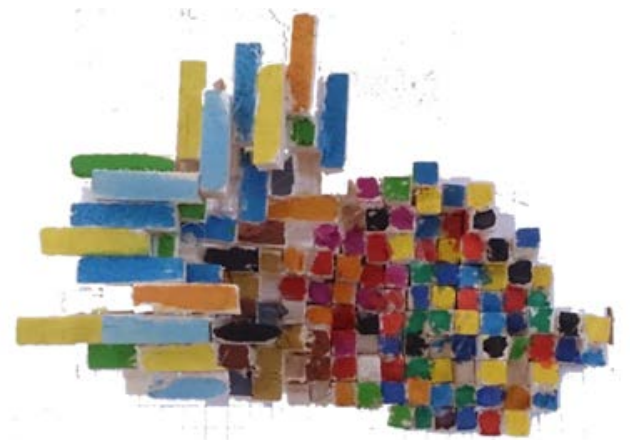

Figure 8: Projects number 8, the sketch for ground and wall combinations. 


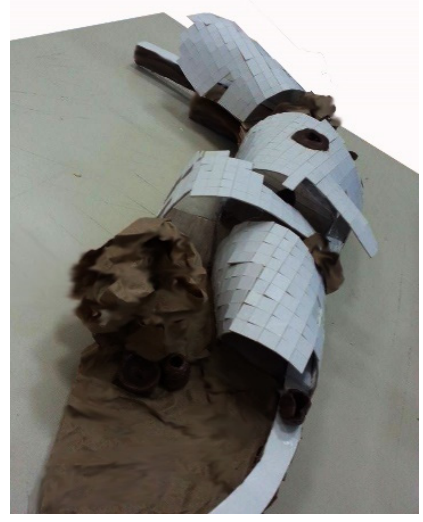

Figure 9: Projects number 8, the final proposal for the architectural elements.
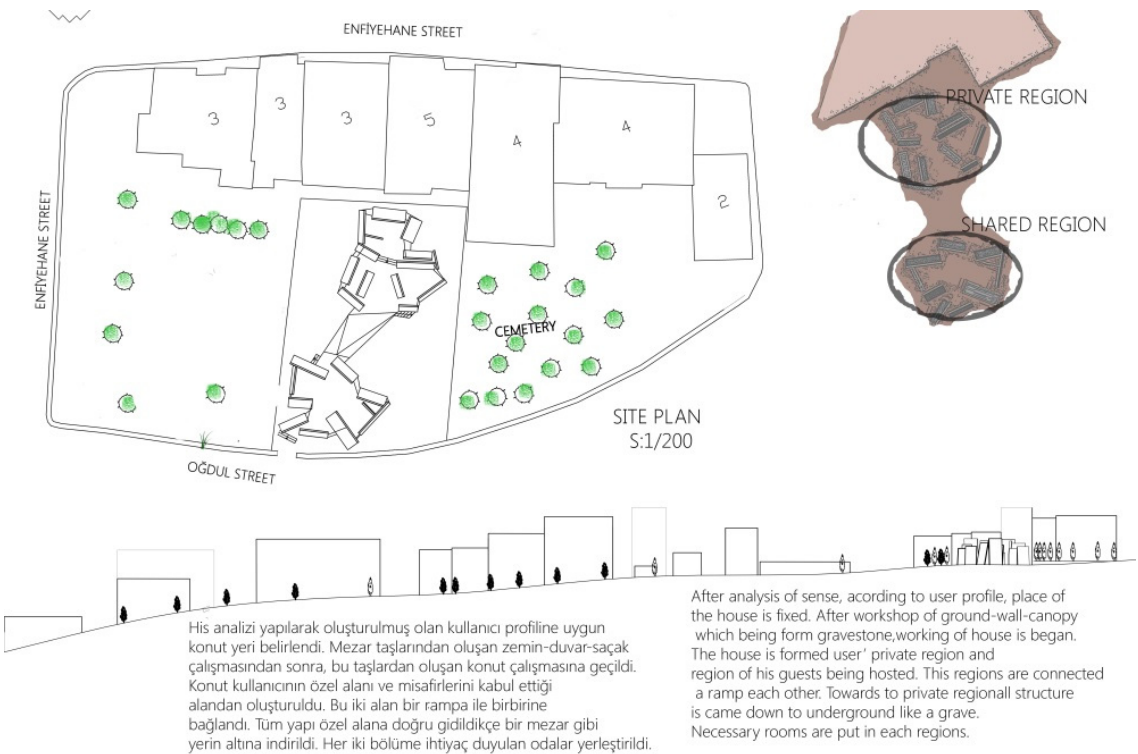

Figure 10: Project number 13, the wall element also create the canopy in the final design proposal.

The scale is a problem; it is very difficult to grasp it. ... With the actual heights of the buildings in situ, you start re-considering your proposal.

The form criterion reflects the gap between the form as a sculpture and the actual setting in the urban tissue. The scale is also part of the form and should fit into the existing urban tissue. 


\subsection{Master plan}

This particular criterion stands for another abstract notion that refers to social and philosophical connotations of the dwelling. Master plan reflects the approach of the designer to the design question. The designer formulates the dialogue of the dwelling with the built environment. The dialogue refers to the threshold (boundaries between the private and public domains of the house), integration of the dwelling with the social setting of the urban tissue, and congruity of the dwelling with the surrounding built environment as well as the perceptions of the users.

\subsubsection{Threshold}

The perception of in-between spaces, intersection of functions and the understanding of public and private domains are sought. The sense of privacy and usage of public space, social interactions in the neighbourhood in relation to the physical thresholds that the ground, wall and canopy elements create are assessed.

\subsubsection{Integration}

The integration notions points out the connections between the private/public spaces, open and closed space bindings. The design is expected to build ties between indoor and outdoor functions. Thus the integration notion refers to the sense of attachment to the current community. Moreover the intricate location of the area and the fluidity of design regarding the natural forms are considered under this concept.

It should be noted that the integration and congruity are parallel notions in this study. Once the design proposal is congruent with the design problem, the design integrates with urban setting. Eight projects out of thirteen proposals are considered to be integrated to the Uskudar setting (both physically and socially). The placement of shared spaces, the size of open area and material selection are evaluated under this notion.

\subsubsection{Congruity}

This component has two perspectives; the first one is indoors where congruity between spaces, functions, flow and circulation are coherent and the second examines the congruity with the present urban silhouette, historical texture, urban context, the configuration of neighbourhood and the surroundings of the house..

Establishing connections between the designed object and the urban context struggling is difficult for students in the early stages of architecture education. The same case is observed for the form and the master plan criteria in the proposals. Project numbers 4, 7, 9, 11 and 12 (Figures 5, 11 and 12) signify that the form might be created completely independently from the surrounding features.

It is observed that the proposals which used the ground, wall and canopy elements in the design succeeded in formulating the threshold notion. It can be inferred that these elements are also tools for creating threshold concept (observed in 3 cases (design numbers 2, 6 and 10) (Figures 11 and 12). 


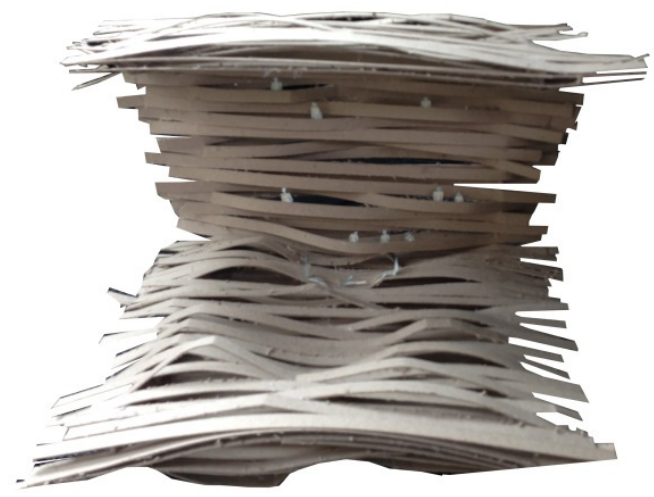

Figure 11: Project number 9, conceptual form for the final design proposal.

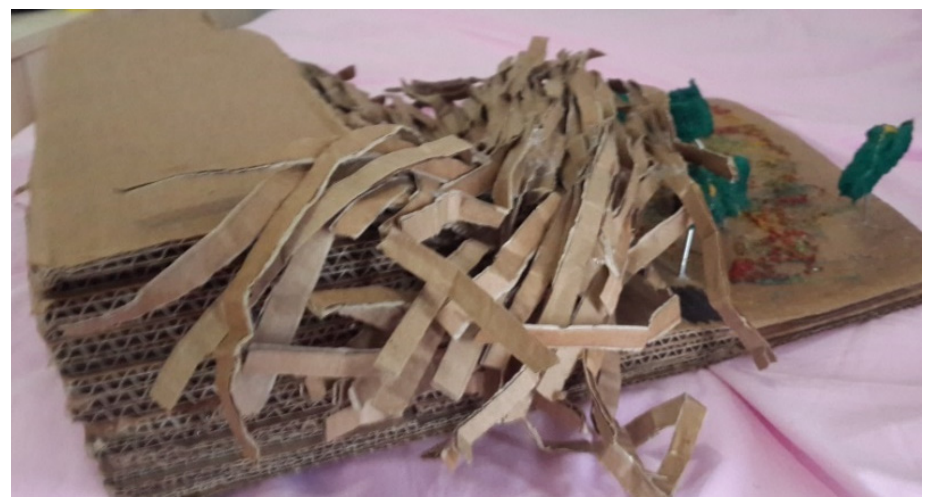

Figure 12: Projects number 10, combination of three architectural elements: ground, wall and canopy.

Hence the works are assessed similar to the method presented by Walliss and Greig [11]; via reports and analyses of student attitudes and responses obtained from focus groups. Regarding design; it is difficult to teach how to think; it can only be acquired via the general habit of reflection [13].

With respect to the "user/function criterion"; it can be inferred that architectural images and situations represent "the relations between the spatial form and everyday life" [2], form criterion refers to the dynamism in the design. The strong bonds between the location and the object address the characteristics of that particular spot; transformation of a location into a place - texture, neighbourhood, social patterns, morphology in the urban context, position of building plot, climate and the unique proposal placed for that single design question. Basically, within the form criteria, the three main elements of a building are considered to formulate 
the entire form. Not only do these elements refer to single components; but to pairs such as ground/wall, wall/canopy or ground/canopy elements. These connections are considered to be the guidelines of design intensities. It is observed that the successful combinations of only two elements out of three might also lead to a competent design solution.

"Form criterion" stands for a "learning by experience" approach. The critical and relational thinking is the most powerful instrument for new idea development; as well as the concept determination and architectural knowledge discovery. In this case "status quos" are questioned. The combinations put forward as different points of views [19]. This makes connections with the project design phase to "remove mental blocks" by brainstorming, analogy and attribute [32]. The students are required to analyse Uskudar from the perspective of fragmented concept keys such as ground, wall, and canopy. As the design pieces are brought together within the theme of threshold. The metaphorical explorations were initially photographic and drawing-based studies parallel to Oxman [32], then model making considering the design themes.

In terms of "Master-plan Criterion"; the abstract notions are addressed with the design itself. The design is seen to be an object, almost an architectural sculpture. Built environment is detached from the circular re-production with the user and the designed space as Habraken [26] suggests. The object is tangible once it is designed; but the urban context is abstract and not familiar and is therefore neglected in the entire formulation. Before the student contemplates the structural and spatial rationality, the urge of tackling the question in the irrational area of his own mind is the basis of this studio. Thus, the purpose is to initiate the area in the designer's mind that has not been surrendered by static elements related to the architecture discipline. A study by Weiss [33] displays the findings through field and interview notes analyses using case-focused analysis. This approach attempts to understand "phenomena by gathering a rich set of data for a limited number of instances to create a thick description" [34], in order to frame the perceptions and organisations of participant activities. Schaffer [23] refers to the analytic descriptions of key elements for the studio experience where the connections among main elements are categorised thematically.

Some proposals display competency in form and user/function criteria which are considered to be architectural formulations and configurations. Nevertheless, with respect to the master plan criteria, the project may be unsuitable. Such cases refer to a very common discussion on the esthetical and functional features of the projects which do not always imply that the design is also congruent to the surrounding characteristics. Madanipour [27] defines a house as a social structure in which private and public realms interconnect. The integration of the design with the urban context, texture and scale create a space of interaction. The levels of interactions are organised by the designer at a certain level. Sommer [35] addresses studied on the seating arrangements and scales of spaces that enhance communal lives.

The students' perceptions towards abstract and tangible notions are explored in the research. Also, the transition of abstract notion, ideas to forms, patterns and usage are reviewed. The difficulties for architectural concepts' comprehension for 
second year design students are found; as tangible aspects are easier to comprehend and react to. The study shows that the three elements (ground/wall/canopy) are considered explicitly. The user/function and master plan criteria urge for further considerations on the complex urban setting. The practice of dialogue limited teacher-talk [36] and encouraged the "learner voice" during round table discussions. The teacher's role was only becoming a "perpetual problem-solver". Problems surface as natural resistance to taking action toward a new possibility [19]. These criteria are taken as problems of the dwelling. Dursun et al. [1] points out that "not only the design solution but also the design process has significant importance in architectural education".

It has been observed that, even though the study takes place in a significant district as Uskudar, students prefer to focus on the ground-wall-canopy combinations; regardless of the surroundings. The biggest challenge is to encourage students to consider the site as an input. It may be inferred that instead of dealing with the abstract significations in a huge world of urban context; students prefer to stay in the comfort zone of familiar elements of a building (ground, wall, canopy) without referring to the dwelling question. Only more than half of the students took the Episodes as a basis to their lonely man's house design and continued till the end with determination. On the other hand, some did not take this initiative work as the basic start point. However; the majority of the competent projects display the traces of participation in the Episodes and concrete data collected from Focus on in-situ fragments. Thus, this study implies that making meaning for the abstract notions urge for hands-on exercises such as model making or silhouette analysis.

\section{Conclusions}

The projects studied in this paper reveal an obscure zone for both the tutor and the student. The feeling of obscurity motivates exploration during the design process. The designers find themselves in a design laboratory full of architectural experiments. These explorations do not have one particular guideline to follow, but every designer formulates his/her own track unique for each design problem. Therefore, the criteria mentioned in this paper are simple tools to create individual guidelines.

Even though the fragmented teaching methodology introduces projects in a concrete plan of teaching, the applications in the studio are rather flexible, and contain the possibility of participation for students. The tutors pay attention to this entity since the attendance and interest of the students are not stable. The fragments provide chances for students to participate in the design process at different stages. This also creates diversification in the final works as well as the tracks taken in order to solve the design problem. The work done becomes a platform that provides open-ended and full of potential dialogues between the designers and the tutors.

Considering the complex mechanism of the human mind, the way of understanding abstract concepts as well as tangible ones changes from person to person. Even though this study displays focus cases on the research question, it 
does not necessarily exemplify every case of architectural design teaching methods. Further research on various abstract notions and longer periods for monitoring the teaching experiences in the studio are crucial. The study can be extended to a multi-year analysis. Even the application at other architecture education institutions can be compared. In this case, different contexts and cultures might reveal different perspectives of design and dwelling. Moreover, an architectural design studio is a laboratory to investigate various teaching and learning tendencies.

\section{References}

[1] Dursun, P., Avc1, O. \& Saglamer, G., Different reflections of architectural knowledge on design. AE Architecture \& Education Journal, 11, pp. 161177. 2014.

[2] Aydinlı, S. \& Avcı, O., Relational thinking that enhance the critical thinking: A studio case based on discovery of knowledge. Educating Architects towards Innovative Architecture, eds C. Spiridonidis \& M. Voyatzaki, EAAE and ENHSA Yıldiz Technical University, Istanbul, 2010.

[3] Freire, P., Pedagogy for Critical Consciousness, Seabury Press: New York, 1973.

[4] Larrivee, B., Authentic Classroom Management: Creating a Community of Learners, Allyn \& Bacon: Boston, MA, 1999.

[5] Boud, D. \& Walker, D., Promoting reflection in professional courses: The challenge of context. Studies in Higher Education, 23(2), 1998.

[6] Freire, P., Pedagogy of the Oppressed, Seabury Press: New York, 1970.

[7] Giroux, H.A., Schooling and the Struggle for Public Life: Critical Pedagogy in the Modern Age, University of Minnesota Press: Minneapolis, 1988.

[8] McLaren, P.L. \& Lankshear, C., Politics of Liberation: Paths from Freire, Routledge: London, 1994.

[9] Misgeld, D., Education and cultural invasion: Critical social theory, education as instruction, and the pedagogy of the oppressed. Critical Theory and Public Life, ed. J. Forester, MIT Press: Cambridge, MA, pp. 77-118, 1987.

[10] Shor, I. \& Freire, P., A Pedagogy for Liberation: Dialogues on Transforming Education, Bergin and Garvey/Greenwood Press: Westport, CT, 1987.

[11] Walliss, J. \& Greig, J., Graduate design education: The case for an accretive model. International Journal of Art \& Design Education, 28(3), pp. 287295, 2009.

[12] Simon, H.A., The Sciences of the Artificial, MIT Press: Cambridge MA, 1996.

[13] Dewey, J., How We Think, Heath \& Co.: Boston, DC, 1933.

[14] Goldschmidt, G., Expert knowledge or creative spark? Predicaments in design education. Expertise in Design: Design Thinking Research Symposium 6 Proceedings, Sydney, 17-18 December, 2003. 
[15] Schön, D.A., Designing as reflective conversation with the materials of a design situation. Knowledge-Based Systems, 5(1), pp. 3-14, 1992.

[16] Forgacs, D. (ed.), A Gramsci Reader: Selected Writings 1916-1935, Lawrence and Wishart: London, 1988.

[17] Hoadley, C. \& Cox, C., What is design knowledge and how do we teach it? Educating Learning Technology Designers: Guiding and Inspiring Creators of Innovative Educational Tools, eds C. DiGiano, S. Goldman \& M. Chorost, Routledge: New York, pp. 19-35, 2009.

[18] Mor, Y. \& Mogilevsky, O., The learning design studio: Collaborative design inquiry as teachers' professional development. Research in Learning Technology, 21, pp. 1-15, 2013.

[19] Larrivee, B., Transforming teaching practice: Becoming the critically reflective teacher. Reflective Practice: International and Multidisciplinary Perspectives, 1(3), pp. 293-307, 2000.

[20] Sagun, A. \& Demirkan, H., On-line critiques in collaborative design studio. International Journal of Technological Design Education, 19, pp. 79-99, 2009.

[21] Lawson, B., How Designers Think: The Design Process Demystified, 4th ed., Architectural Press: Boston, 2003.

[22] Oxman, R., Educating the designerly thinker. Design Studies, 20, pp. 105122, 1999.

[23] Shaffer, D.W., Portrait of the Oxford design studio: An ethnography of design pedagogy. WCER Working Paper No. 2003-11, University of Wisconsin-Madison, USA: Wisconsin Centre for Education Research School of Education, 2003.

[24] Brookfield, S.D., Becoming a Critically Reflective Teacher, Jossey-Bass: San Francisco, 1995.

[25] Rapoport, A., House Form and Culture (Foundations of Cultural Geography Series), Prentice Hall, Englewood Cliffs, NJ, 1969.

[26] Habraken, N.J., The Structure of the Ordinary, Form and Control in the Built Environment, ed. J. Teicher, MIT Press: New York, 1998.

[27] Madanipour, A., Public and Private Spaces of the City, Routledge: New York, 2003.

[28] De La Harpe, B., Peterson, F., Frankham, N., Zehner, R., Forsyth, G., Musgrave, E. \& McDermott, R., Assessment focus in studio: What is most prominent in architecture, art and design? The International Journal of Art and Design Education, 28(1), pp. 37-51, 2009.

[29] Logan, C., Metaphor and pedagogy in the design practicum. International Journal of Technological Design Education, 18, pp. 1-17, 2007.

[30] Shaffer, D.W. \& Resnick, M., Thick authenticity: New media and authentic learning. Journal of Interactive Learning Research, 10(2), pp. 195-215, 1999.

[31] Ehmann, D., Using assessment to engage graphic design students in their learning experience. 2005 Evaluations and Assessment Conference Proceedings, Sydney, 30 November-1 December, 2005. 
[32] Oxman, R., Think-maps: Teaching design thinking in design education. Design Studies, 25(1), pp. 63-91, 1999.

[33] Weiss, R.S., Learning from Strangers: The Art and Method of Qualitative Interviewing, Free Press: New York, 1994.

[34] Geertz, C., The Interpretation of Cultures: Selected Essays, Basic Books: New York, 1973.

[35] Sommer, R., Personal Space: The Behavioural Basis of Design, PrenticeHall International: London, 1969.

[36] Shor, I., Empowering Education: Critical Teaching for Social Change, University of Chicago Press: Chicago, 1992. 